\title{
Kompleks Problem Çözme Üzerine R Programı ile Bir Bibliyometrik Analiz
}

\section{A Bibliometric Analysis employing the R Program of Complex Problem Solving}

\begin{abstract}
Volkan AŞKUN * Rabia Çi̇EL ${ }^{* *}$

Öz: Özellikle gelecekteki eğitim ve çalışma hayatı üzerine son yıllarda yapılan çalışmalarda kompleks problem çözme önemli yer edinmektedir. Dünya Ekonomik Forumu raporuna göre önümüzdeki beş yıl içinde talep edilecek beceriler listesinde kompleks problem çözme dikkat çekmektedir. Türkiye'nin listesinde ise kompleks problem çözme beşinci sırada değerlendirilmektedir. Rapora göre önümüzdeki dönemde hem akademik alanda hem de çalışma yaşamında bu konunun gündemde olacağı belirtilmektedir. Sistematik yazın taramaları araştırma alanı ya da konusu ile ilgili önemli değişkenleri keşfetmek, yapılması gerekenleri yapılanlardan ayırt etmek ve dahası araştırmacılar için önerilerin belirlenmesinde önemli fayda sağlayan yöntemlerdendir. Bu bağlamda bu çalışmada sistematik yazın tarama yöntemlerinden birisi olan bibliyometri kullanılarak kompleks problem çözme üzerine bir sistematik yazın taraması gerçekleştirilmiştir. Çalışma, Scopus veri tabanında yer alan dergilerde 1999-2018 yılları arasında yayınlan "complex problem solving" anahtar kelimelerini içeren 166 makalenin R programlama dilini kullanarak bibliyometrik analizini yapmaktadır. Aynı zamanda kompleks problem çözme alt alanları ile zamanda gelişimi arasındaki ilişkileri göstermek için içerik analizi kullanılmaktadır. Çalışma daha çok kaynak etkileri, eşdizimlilik ağı, ortak atıf, yazar iş birliği üzerine odaklanmaktadır. Araştırma sonuçlarının kompleks problem çözme ile ilgili gelecekteki çalışmalara ışık tutacağı öngörülmektedir.
\end{abstract}

Anahtar sözcükler: Kompleks problem çözme, ağ analizi, ortak atıf analizi, bibliyometrik analiz

Abstract: Complex problem solving has gained a significant place especially in the studies conducted concerning education and working life in the future, According to the report of World Economic Forum, complex problem solving in the list of skills to be demanded in the next five years is noteworthy. In Turkey's list of complex problem solving is considered the fifth. According to the report, it is stated that this issue will be on the agenda both in academic and working life in the upcoming period. Systematic literature surveys are important methods to discover important variables related to the field or to the subject of research, to distinguish what should be done from what is done, and, moreover, to determine recommendations for researchers. In this study, a systematic literature survey on complex problem solving was conducted using bibliometry, which is a method of systematic survey of the literature. The study uses bibliometric analysis of 166 articles recording complex problem solving keywords published the journals published on the Scopus database between 1999-2018. Content analysis is also used to demonstrate the relationship between complex problem solving sub-areas and the development of complex problem solving research over time. This study largely focuses upon resource impacts, colloboration network, citation, and author collaboration. It is intended that the results of this research will cast a light on future studies concerning complex problem solving.

Keywords: Complex problem solving, network analysis, co-citation analysis, bibliometric analysis

\footnotetext{
* PhD. Candidate, Akdeniz Üniversitesi, Sos. Bil. Ens., Sos. Pol. ve Çalış. İliş. Prog., Antalya, volkanaskun@gmail.com https://orcid.org/0000-0003-2746-502X

** Prof. Dr., Akdeniz Üniversitesi, İİBF, Çalışma Ek. ve End. İliş. Bölümü, Antalya, rabiacizel@akdeniz.edu.tr https://orcid.org/0000-0002-6381-2503
} 


\section{Literatür Taraması}

Artan küreselleşme ve teknolojik gelişmelerin yaşandığı günümüzde, insanlar gündelik yaşamda birçok sorunla, ulaşmaları gereken birçok hedefle ve düşünülebilecek birçok eylemle karşı karşıya kalmaktadırlar. Bu karmaşık problemleri çözmek için insanlar genellikle sistemlerin yapısı ve dinamikleri ile ilgili karmaşık yapılar hakkında bilgi edinmek ve uygulamak zorunda kalmaktadırlar. Karmaşık Problem Çözme (KPÇ) örnekleri, bilinmeyen karmaşık teknik cihazlar (yeni bir cep telefonu, bilgisayar, yeni teknolojik ürünler vb.) kullanımı, karmaşık organizasyonların (şirketler veya topluluklar) yönetimi veya karmaşık ortamlar (hava durumu tahminleri, siyasi seçimler veya borsa vb.) şeklinde karşımıza çıkmaktadır (Fischer et al. 2012, 21). İnsanların karşılaştığı sorunları çözmeye yönelik olarak yapılan araştırmalarda KPÇ, 1970 'lerden bu yana basit, statik, iyi tanımlanmış ve akademik sorunlarda vurgu yapılan önemli bir konu olarak ele alınmaktadır (Wenke et al. 2005, 167).

KPÇ, insanların veya grupların durumlarının tam yapısının ve özelliklerinin nispeten bilinmediği karmaşık, dinamik ve şeffaf olmayan durumlardaki davranışlarıyla ilgilidir (Dörner \& Reither 1978, 528). Personel seçimi için KPÇ araştırma paradigmalarının uygulanmasındaki temel amaç, daha üst düzey düşünme süreçleri ve becerileri gerektiren daha karmaşık, anlamlı, bütünleştirici ve gerçekçi görevleri kullanmaktır. Personel seçme ve eğitim uygulamaları, araştırma paradigmalarını bir teknoloji olarak benimsemektedir ve ortak bir KPÇ tanımı içermemektedir (Funke 1991, 187). KPÇ, bir sistemin bir veya daha fazla hedef değişkenini bir dizi kararla optimize etme görevidir. Burada sözü geçen sistem, birkaç değişkenden oluşmakta ve birkaç alternatif eyleme sahip olmaktadır. Sistem veya sistem durumları hakkındaki bilgiler eksik veya zamanı geçmiş bir şekilde gelmektedir (Huber 1994, 140). KPÇ, bir sistemin değişkenleri arasındaki nedensel ilişkilerin tanınmasını gerektiren bilişsel ustalığı içeren görev sınıfını temsil etmektedir (Beckmann \& Guthke 1995, 180).

Karmaşık problem çözme süreci bilgi edinme ve bilgi uygulama olarak iki temel aşamadan oluşmaktadır. Bilgi edinme aşamasında, bireyler önceden bilinmeyen karmaşık bir sistemin dinamiklerini ve değişkenlerini gözlemler ve problem durumunun bir temsilini geliştirir (Greiff et al. 2013, 72). Bilgi uygulama aşamasında ise bireyler, karmaşık sistemi kontrol etmek ve istenen duruma dönüştürmek için sistem bilgilerini kullanır ve sürekli olarak günceller (Fischer et al. 2015, 2). KPÇ'deki ana bilişsel süreçler; hedef belirleme, bağlantılar kurma ve hipotez testlerini içermektedir (Care et al. 2016, 252). KPÇ sürecinin etkileşimli doğası, araştırmacıları zamana ve problem çözücünün girdisine bağlı olarak geçici değişebilen karmaşık problem senaryolarını kullanmaya zorlamaktadır. Bu nedenle, bilgisayarlı karmaşık problem simülasyonları son dönemdeki çalışmalarda KPÇ becerilerinin hem değerlendirilmesinde hem de geliştirilmesinde faydalı bir araç olarak görülmektedir. Bu bağlamda KPÇ alanında yapılan çalışmalara bakıldığında inovasyon (Baggen et al. 2015; Conley et al. 2017; Marshall 2009; Weigelt \& Sarkar 2012), dinamik karar verme (Danner et al. 2011; Dörner \& Güss, 2013; Güss et al. 2009; Schoppek \& Fischer, 2017), genetik laboratuvarı (Greiff et al. 2015; Sonnleitner et al. 2014), bilgisayar tabanlı değerlendirme (Schult et al. 2017; Wüstenberg et al. 2014), karmaşıklık (Beckmann et al. 2017; Hagemann \& Kirschke, 2017), biliş (Nair \& Ramnarayan, 2000; Sinnott et al. 2017), muhakeme (Fischer et al. 2015; Frischkorn et al. 2014), kültür (Güss, 2011) yazar anahtar kelimeli çalışmaların alana güçlü katkı sağladığı görülmektedir.

KPÇ becerilerinin önemi, Uluslararası Öğrenci Değerlendirme Programı (PISA) çerçevesine dahil edilmelerinde yansıtılmaktadır. PISA $(2018,3)$ dünya çapında eğitim sistemlerini değerlendirmeyi amaçlayan uluslararası bir ankettir. 2000'den beri, PISA 15 yaşındaki öğrencilerin okuma, fen ve matematik alanlarında yeterliliklerini test etmektedir. 2003 yılında, KPÇ becerilerini genel bir bilgi alanı olarak ölçmek için PISA araştırmasına yaratıcı bir problem çözme testi de dahil edilmiştir (Greiff et al. 2014, 75). Diğer yandan V. Hagemann \& Kluge (2017) 116 
kişiyle yaptıkları çalışmayla, takımlar halinde başarılı karmaşık problem çözme için takım süreci taleplerinin yerine getirilmesinin önemini göstermektedir. Caner et al. (2017) ABD’de ilaç firmalarıyla yürüttükleri çalışmada, KPÇ'nin şirketlerde iyi hiyerarşik yönetişim altında çözüldüğünü göstermekte ve şirketlerin genel olarak bu teoriyle uyum içinde olduklarını varsaymaktadırlar. Bununla birlikte KPÇ’nin çeşitli kullanışlı uygulamalara yönelik çözümler ürettiğini vurgulamaktadırlar. Kirschke et al. (2017) Alman su yönetişim sisteminde var olan 37 farklı problemin çözümünde KPÇ'nin önemini belirttikleri çalışmada ise kamu kurumlarında da bu konunun önemle işlendiğini göstermektedirler. Ederer et al. (2015), 2012-2014 yılları arasında Almanya, İspanya, Güney Afrika, Danimarka, Slovakya, İsviçre ve Fransa'da 16 şirkette topladıkları veriler ile KPÇ’nin şirketlere önemli ekonomik getiri sağladıklarını göstermektedirler.

40 yıldan uzun bir süredir, KPÇ yeni bir psikolojik araştırma konusu olmuştur. Bu süre zarfında, insanların karmaşık, dinamik ve belirsiz durumlarla nasıl başa çıktıklarının analizine ilk vurgu yapılmıştır. Karmaşık problem çözme, hayatını paylaşacak doğru kişiyi bulmaktan başlayıp, sadece para kazanmak için değil aynı zamanda bizi mutlu eden bir kariyer seçmek gibi günlük hayatımızın bir parçası haline gelen kararlarımızda etkili olmaktadır. KPÇ aynı zamanda iklim değişikliği, nüfus artışı, savaş tehdidi, doğal kaynakların kullanımı ve dağıtımı gibi konular olarak da ele alınmaktadır. Özetle, birçok toplumsal zorluk karmaşık problemler olarak görülebilmektedir.

Bilimsel anlamda etkili olabilmek için bilimsel araştırmaların birbiri arasında iletişimin olması gerekir. Kitaplar, kitap bölümleri ve dergilerdeki makaleler, bilim insanlarının ürettikleri araştırma çıktılarından bazılarıdır. Bilim insanlarının, yeni bir araştırma keşfinde önceliğini belirlemek veya katkılarının orijinalliğini göstermek için atıf ve referanslar kullanmaları gerekmektedir (Merton 1957, 637). Atıf ve referansların öncüllerin onayını alması, yeni bir fikrin kökenini takip etmesi, yeni bulguları geçerli bulgulardan ayırt etmesi gibi birçok işlevi vardır. Bilimsel çıktılar, referanslar ve atıflar, bibliyometrik göstergelerin üzerine oturtulduğu ham gerçekleri temsil eder. Bibliyometrik göstergeler ilk olarak bilimin nicel incelemesi için geliştirilmiştir (de Bellis 2014, 25). Günümüzde ise araştırmacılar, önceki bulguları anlamak ve düzenlemek için farklı nitel ve nicel literatür tarama yaklaşımlarını kullanmaktadırlar. Bunların arasında bibliyometrik analiz bilimin, bilim insanlarının veya bilimsel faaliyetlerin istatistiksel olarak ölçülmesine dayanan sistematik, şeffaf ve tekrarlanabilir bir inceleme süreci sağlama potansiyeline sahiptir. Diğer tekniklerin aksine, bibliyometrik analiz daha objektif ve güvenilir analizler sağlamaktadır (Aria \& Cuccurullo 2017, 960). Crane (1972)'e göre yeni bilgilerin, kavramsal gelişmelerin ve verilerin büyüklügüne bibliyometrik analiz uygulanarak, zaman içinde eğilimleri ortaya çıkarmak, temaları araştırmak, disiplinlerin sınırlarındaki değişimleri tespit etmek, üretken araştırmacılar ve kurumları en iyi şekilde saptayarak mevcut araştırmanın büyük resmini ortaya koymak mümkün olmaktadır. Bu bağlamda bibliyometrik analizlerin (1) yeni araştırma yöntemleri aramak, (2) araştırma önerileri geliştirmek, (3) araştırma alanlarının ya da konularının değişkenlerini keşfetmek, (4) araştırmacılar, dergiler ve ülkeler arasındaki ilişkileri belirlemek, (5) fikir ve teorileri uygulamalar ile ilişkilendirmek gibi faydaları vardır.

Dünya Ekonomi Formu İşlerin Geleceği Raporuna (2018) göre Türkiye'de gelecek beş y1l içinde talep edilecek beceriler listesinde beşinci sırada yer alan KPÇ gelecek yıllarda hem akademik alanda hem de çalışma yaşamında oldukça önemli olacağ 1 gözlenmektedir. $\mathrm{Bu}$ bağlamda çalışmanın amacı bibliyometrik analizle KPÇ’nin 20 yıllık tarihsel gelişimi ortaya çıkararak bu alanda çalışacak araştırmacılara yol haritası sunabileceği düşünülmektedir. Çalışma kapsamındaki aşağıdaki sorulara cevaplar aranmaktadır:

(1) KPÇ'nin kavramsal haritası nedir? 
(2) Bilimsel araştırmacıların, ülkelerin ve akademik dergilerin KPÇ'deki üretkenliği nedir?

(3) KPÇ’de yazarlar, dergiler ve ülkeler arasındaki işbirlikleri nedir?

\section{Yöntem}

Araştırmada sistematik yazın tarama yöntemlerinden birisi olan bibliyometrik analiz kullanılmıştır. Bibliyometrik analiz için Cobo et al. (2011) ve Börner et al. (2005)'in çalışmalarında açıklanan genel bibliyometrik yöntemler takip edilmektedir. Araştırmada "complex problem solving" anahtar kelimeleri hakem denetimli literatür veri tabanı olan Scopus (www.scopus.com) üzerinde taranmıştır. 1999 - 2018 yılları arasında uluslararası dergilerde yayınlanan 166 orijinal araştırma makalesi ele alınmıştır. Veriler, tek bir kaynakça veri tabanında toplanması ve çalışma içindeki göndermelerde bu veri tabanı temel alınarak kaynakça ile ilgili bilgilerin istenilen yerde istenilen şekilde görünmesi sağlanması bakımından BibTeX şeklinde bilgisayara kaydedilmiştir.

Erişilen makaleler anahtar kelimeler ve doküman başlıklarında kullanılan kavramlar üzerinden incelenmiştir. Anahtar kelimelere dair analizler için sosyal ağ analizi ile ortak atıf, işbirliği, eşdizimlilik analizlerinden faydalanılmıştır. Diğer yandan alanın gelişmesine yönelik ana gelişme noktalarını belirleyebilmek adına KPÇ alanında kaynak etkileri ele alınmış ve değerlendirilmiştir. Analizlerin yürütülmesinde R programlama dili, görsellerin oluşturulmasinda ise ggplot2 (https://cran.r-project.org/) kütüphanesi kullanılmıştır.

\section{Bulgular}

Keywords Plus (KWS), belirtilen makalelerin başl1klarından otomatik olarak oluşturulan dizin terimleridir. KWS terimleri, bibliyografyada bir kereden fazla görünmeli ve çok kelimeli ifadelerden tekil terimlere sıralanmalıdır. KWS, geleneksel anahtar kelime veya başlık alımını artırır. Bu bağlamda çalışmada 166 makalenin KWS'sine bakılmıştır ve Şekil 1'de "problem çözme" en sık kullanılan kelime olarak gözlenirken, sonrasında sırasıyla "öğrenciler, insan, karar verme, kompleks problemler, yapay zekâ, biliş ve proje yönetimi” kelimelerinin yüksek sıklıkta kullanıldığı gözlenmektedir.

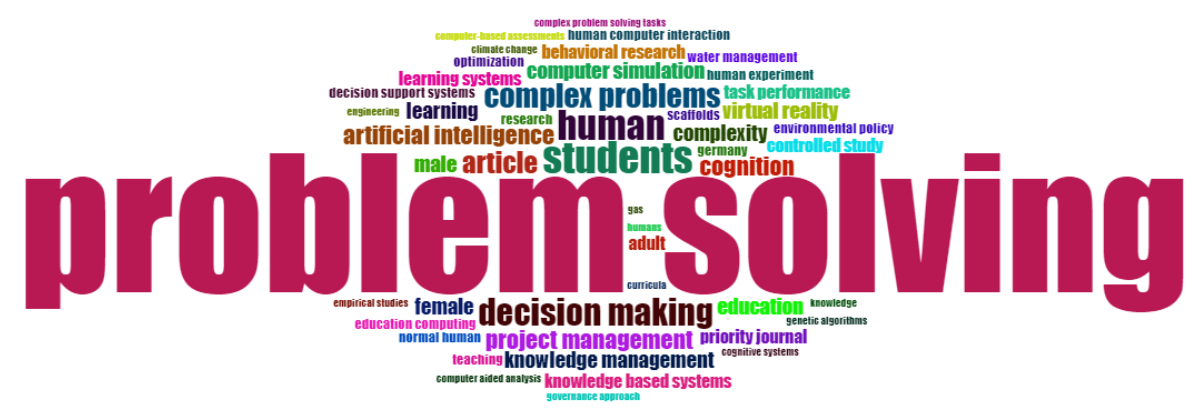

Fig. 1. Kelime Bulutu

Tablo 1'de, 1999-2018 yılları arasında KPÇ için Intelligence dergisinin her değerde daha etkili dergi olduğu gözlemlenirken sonrasında toplam atıfta Journal of Cleaner Production $(\mathrm{TC}=162)$ ve Journal of Educational Psychology $(\mathrm{TC}=106)$ dergileri, toplam makale sayısında Frontiers in Psychology $(\mathrm{NP}=9$ ), Computers in Human Behavior ( $\mathrm{NP}=7$ ) ve Educational Technology Research and Development (NP =7) dergilerinin etkili olduğu görülmektedir. 
Tablo 1. Kaynak Etkileri

\begin{tabular}{|c|c|c|}
\hline Kaynak & $h \_$index $g \_$index & m_index $\mathrm{TC}^{*}$ \\
\hline Intelligence & 13 & 0,61 \\
\hline Frontiers in Psychology & 5 & 0,50 \\
\hline Computers in Human Behavior & 7 & 0,43 \\
\hline Educational Technology Research and Development & 7 & 0,50 \\
\hline Learning and Individual Differences & 6 & 0,57 \\
\hline Journal of Educational Psychology & 5 & 0,57 \\
\hline Zeitschrift fur Padagogische Psychologie & 5 & 0,31 \\
\hline Computers and Education & 4 & 0,38 \\
\hline International Journal of Lifelong Education & 3 & 0,60 \\
\hline Instructional Science & 3 & 0,14 \\
\hline International Journal of Project Management & 3 & 0,50 \\
\hline Applied Psychological Measurement & 1 & 0,13 \\
\hline British Journal of Educational Technology & 2 & 0,18 \\
\hline Cognitive Science & 2 & 0,20 \\
\hline European Journal of Psychological Assessment & 2 & 0,40 \\
\hline Jisuanji Xuebao/Chinese Journal of Computers & 2 & 0,25 \\
\hline Journal of Cleaner Production & 2 & 0,14 \\
\hline Journal of the Association of Information Systems & 2 & 0,15 \\
\hline Simulation and Gaming & 1 & 0,06 \\
\hline Strategic Management Journal & 2 & 0.25 \\
\hline \multicolumn{3}{|c|}{$\begin{array}{l}\text { Figür 2.'de, KPÇ alanında en çok atıf alan ülke Almanya yer almaktadır, sonra } \\
\text { Lüksemburg ve ABD gelmektedir. Diğer yandan bu alanda en çok çalışmanın bu } \\
\text { tarafından yapıldığ görülürken makale başına en çok atıf alarak etkili olan ülke A } \\
\text { olduğu görülmektedir. Aynı şekilde sırasıly Kanada, İspanya ve Fransa makale baş } \\
\text { toplamda en çok atıf alan ülkelerden daha etkili oldukları görülmektedir. }\end{array}$} \\
\hline 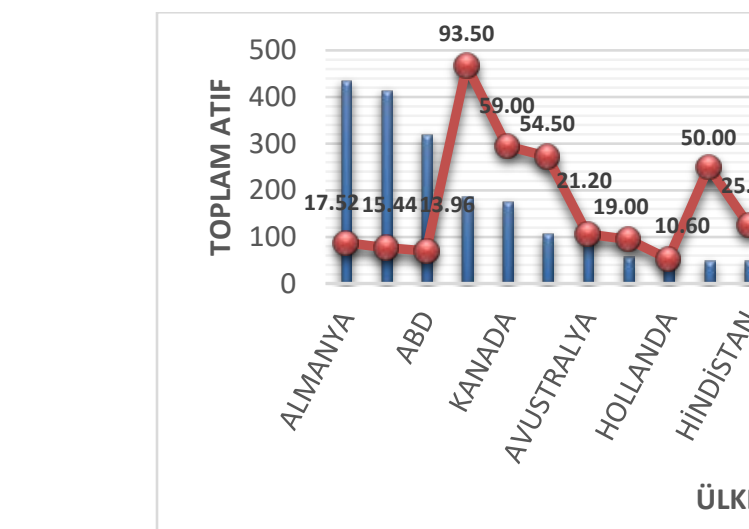 & 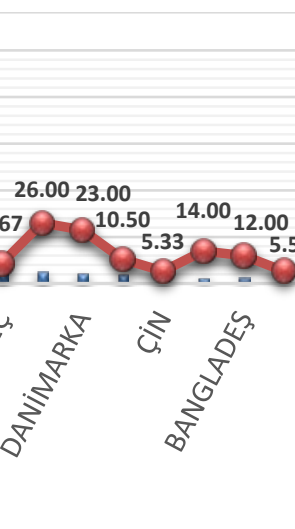 & 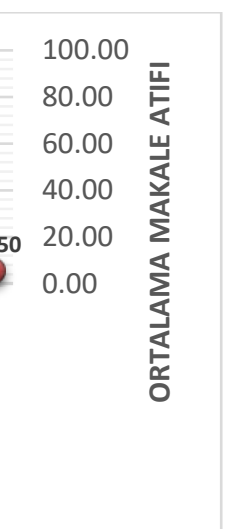 \\
\hline
\end{tabular}

Fig. 2. En Çok Atıf Alan Ülkeler 


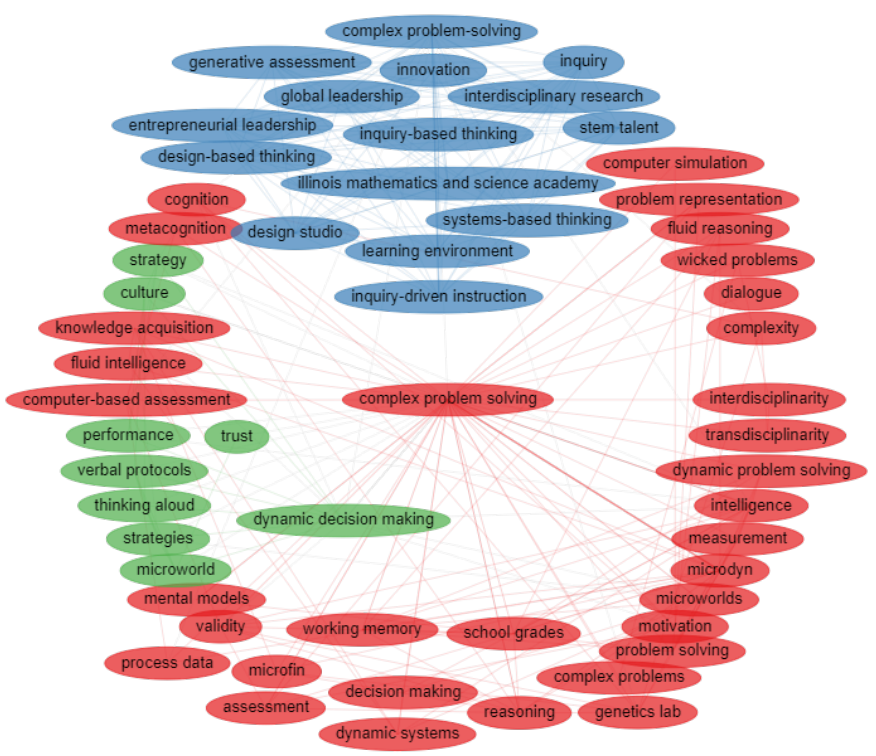

Fig. 3. Eşdizimlilik ağı - Yazar anahtar kelimeleri

Yazar anahtar kelime kavramlarının birlikte kullanımını inceleyebilmek için eşdizimlilik ağına bağlı veri görselleştirilmesi uygulanmıştır. Görselleştirme aşamasında verinin okunabilmesini kolaylaştırmak için en az iki kez ve daha çok kullanılan terimler Şekil 3.'te gösterilmiştir. Her bir kavram birlikte kullanılma sayısına göre ilişkilendirilmiş ve aralarındaki ilişkiyi gösterir çizgi ilgi sayısına göre renklendirilmiştir. Buna göre KPÇ için 'complex problem solving' (küme $=1$, btwc $($ arasındaki merkezilik $)=1088,65)$ merkezde en güçlü şekilde yer alırken sonrasında 'innovation' (küme $=2$, btwc $=383,31$ ), 'intelligence' (küme $=1$, btwc $=53,89$ ), 'dynamic decision making' (küme $=3$, btwc $=42,46$ ) kelimelerinin güçlü merkeziyette olduklar1 görülmektedir. Küme 1 de ise 'complex problem-solving' ( $b t w c=166,11)$ şeklinde kullanımı dikkat çekmektedir.

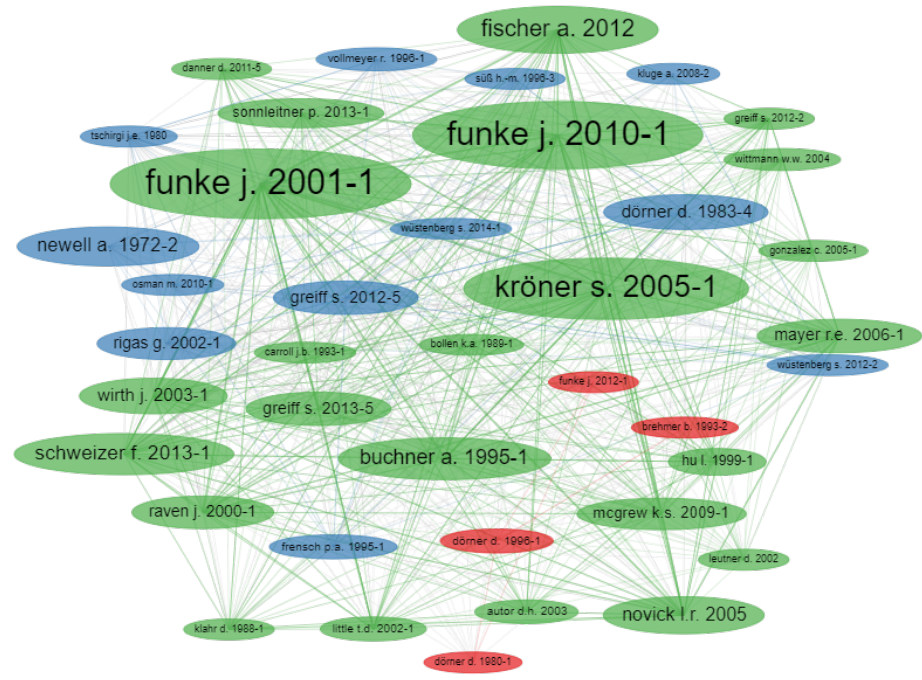

Fig. 4. Ortak Atıf - Bilimsel Yazı

KPÇ için 40 bilimsel yazı için ortak atıf analizi yapılmış ve bunun için "Walktrap" kümeleme algoritması kullanılmıştır. Elde edilen sonuçlar Şekil 4.’te görüldüğü üzere, sırasıyla Funke, J. 2001-1 (küme = 3, btwc= 8,44), Funke, J. 2010-1 (küme = 3, btwc= 7,75), Dörner, D. 1983-4 
(küme $=2$, btwc= 4,32), Schweizer, F. 2013-3 (küme = 3, btwc= 3,99), Kröner, S. 2005-1 (küme $=3$, btwc $=3,85$ ) şeklinde önemli bir konuma sahipken 1. kümede Dörner, D. 1996-1 (btwc $=0,97$ ) etkili görünmektedir.

KPÇ için 40 bilimsel yazı için ortak atıf analizi yapılmış ve bunun için "Walktrap" kümeleme algoritması kullanılmıştır. Elde edilen sonuçlar Şekil 4.’te görüldüğü üzere, sirasıyla Funke, J. 2001-1 (küme = 3, btwc= 8,44), Funke, J. 2010-1 (küme = 3, btwc= 7,75), Dörner, D. 1983-4 (küme = 2, btwc= 4,32), Schweizer, F. 2013-3 (küme = 3, btwc= 3,99), Kröner, S. 20051 (küme $=3$, btwc $=3,85$ ) şeklinde önemli bir konuma sahipken 1. kümede Dörner, D. 1996-1 (btwc $=0,97$ ) etkili görünmektedir.

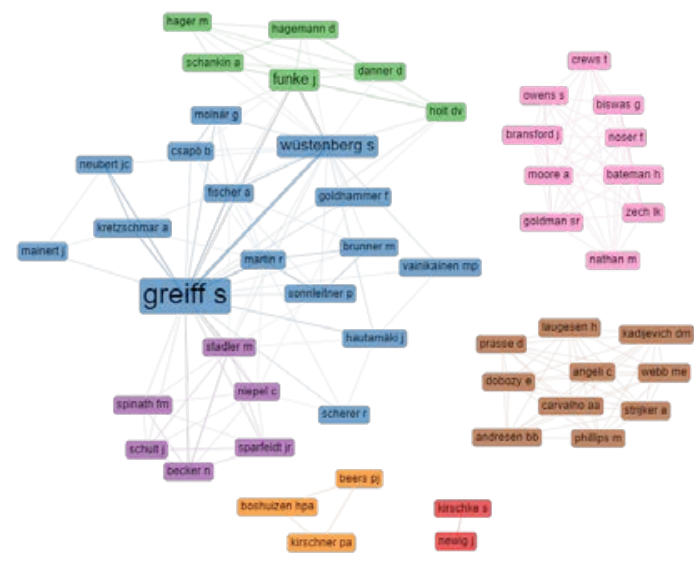

Fig. 5. Yazar İşbirliği

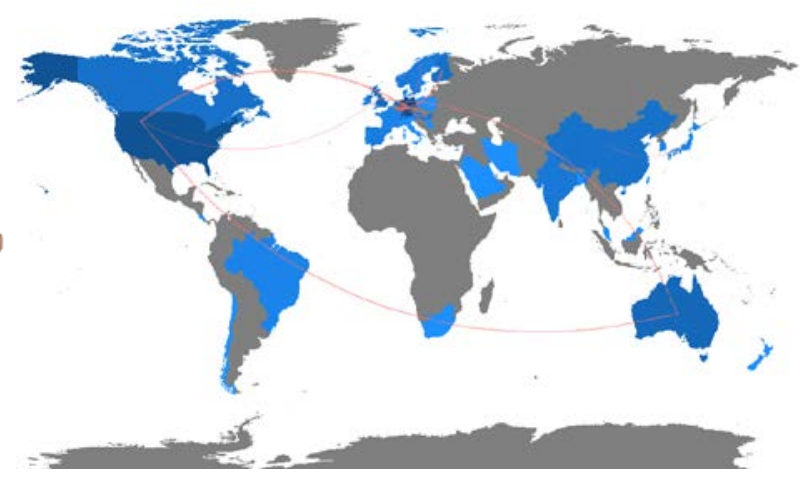

Fig. 6. Dünya İşbirliği Haritası

KPÇ için 50 yazar kısıtlaması ile yazar işbirliği analizi yapılmış ve bunun için "Walktrap" kümeleme algoritması kullanılmıştır. Elde edilen sonuçlar Şekil 5.'te görüldüğ̈̈ üzere, Greiff $S$. (küme $=2$, btwc $=166,73$ ) ile en güçlü işbirliği olan yazar olarak değerlendirilirken aynı kümede yer alan Wustenberg S. (btwc=69,06) sonrasında en güçlü işbirliği olan yazar olarak değerlendirilmektedir. Üçüncü kümede Funke J. (btwc= 25,66) ve dördüncü kümede Stadler M. $(\mathrm{btwc}=4,40)$ kümelerinde en güçlü işbirliği olan yazarlar olarak dikkat çekmektedir.

KPÇ alanında işbirliği yapmış ülkelerin yoğunluklar Şekil. 6' da ifade edilmiştir. Buna göre en fazla işbirliği Almanya - Lüksemburg ( $\mathrm{f}=24)$, Almanya - $A B D(f=5)$, Lüksemburg Finlandiya ( $f=5$ ), Avustralya - Birleşik Krallık ( $f=3$ ), Almanya - Macaristan ( $f=3$ ), Macaristan Lüksemburg ( $\mathrm{f}=3)$, ABD - Avustralya $(\mathrm{f}=3)$ şeklinde analiz edilmiştir. $\mathrm{Bu}$ bağlamda bakıldığında KPÇ alanına en fazla işbirliği katkısı Almanya, Lüksemburg, Avustralya ve ABD ülkelerinden geldiği görülmektedir.

\section{Sonuç ve Tartışma}

Son 30 yılda, karmaşık problem çözme (KPÇ) etiketi altında Avrupa'da düşünme ve problem çözme psikolojisinin yeni bir parçası ortaya çıkmıştır. Bu makale geniş bakış açısı ile konu ile ilgili kavramların gözden geçirilmesini sağlamaktadır. Bu seçici derlemenin temel amacı, şu ana kadar uluslararası alanda yapılan araştırma bulgularının ve belirli araştırma geleneklerinin bir sunumunu yapmaktır.

KPÇ için yapılan analizlere bakıldığında bu alana en çok katkı sağlayan dergilere bakıldı$\breve{g}$ Inda Intelligence $(\mathrm{NP}=13)$, Frontiers in Psychology $(\mathrm{NP}=9)$, Computers in Human Behavior $(\mathrm{NP}=7)$, Educational Technology Research and Development (NP=7), Learning and Individual Differences $(\mathrm{NP}=6)$ ve Journal of Educational Psychology $(\mathrm{NP}=5)$ dikkat çekmektedir. Bunlar haricinde ise Journal of Cleaner Production dergisi ise sadece iki makale ile bu bahsi geçen dergilerden daha çok atıf almıştır. Buna neden olan ise KPÇ alanında en çok ikinci atıf alan Avusturya'dan Steiner ve Posch (2006) çalışmasının bu dergide yayınlaması olarak 
değerlendirilebilir.

Ülkelerin KPÇ alanına katkılarına bakıldığında Almanya'nın hem makale sayısında (NP=88) hem de atıf sayısında $(\mathrm{TC}=438)$ bu alana katkısının güçlü olduğu gözlenmektedir. Almanya'yı sırasıyla takip eden ülkeler ise şu şekildedir: $\mathrm{ABD}(\mathrm{NP}=72, \mathrm{TC}=321)$, Lüksemburg $(\mathrm{NP}=43$, $\mathrm{TC}=417)$, Avusturalya $(\mathrm{NP}=18, \mathrm{TC}=187)$ ve Kanada $(\mathrm{NP}=10, \mathrm{TC}=177)$. Türkiye'nin ise KPÇ alanına herhangi bir katkısı gözlenmemektedir.

Yazarların kullandığı anahtar kelimeler için eşdizimlilik analizi sonucuna göre, KPÇ’nin ortak kümede yer aldığı kelimelere bakıldığında zekâ, genetik lab, bilgisayar tabanlı değerlendirme, karmaşıklık, biliş, akıl yürütme, kültür, strateji, çalışan bellek, bilgi edinme, dinamik sistemler, motivasyon dikkat çekmektedir. Bu alanda ileride yapılacak çalışmalarda bu konuların baskın olacağı düşünülmektedir.

Bilimsel yayınlar için ortak atıf analizine göre bakıldığında yeşil kümede yer alan Alman araştırmacı Funke (2001)'nin insan kararını analiz etmenin aracı olarak dinamik sistemler ile yapmış olduğu çalışma en güçlü etkiyi gösterirken yine Funke (2010)'nin KPÇ bağlamında karmaşık biliş ve duygu ilişkisini tartıştığı çalışmasının bu alana katkısının güçlü olduğu gözlenmektedir. Yine aynı kümede yer alan Schweizer et al. (2013)'nin 393 Alman lise öğrencisi ile yaptığı çalışma ve Kröner et al. (2005)'nin 9-12 yaş arası 101 Alman lise öğrencisi ile yaptığı çalışma en çok ortak atıf alan çalışmalardır. Mavi kümede ise Dörner \& Kreuzig (1983)'nin zeka ölçütleriyle farklı problemleri çözmedeki başarı ölçütlerini karşılaştırdığı çalışma ile kırmızı kümede Dörner (1996)'ın karmaşı durumlarda hatayı tanımak ve önlemek adına yayımladığı kitap diğer en çok ortak atıf alan bilimsel yayınlardır.

Yazarların işbirliği analizinde ise Lüksemburg'dan Greiff, S. (NP=35), Martin, R. (NP=9) Stadler, M. (NP=7) ve Almanya'dan Wüstenberg, S. $(\mathrm{NP}=16)$ ve Funke, J. $(\mathrm{NP}=15)$ KPÇ alanına ciddi katkısı olan yazarlar olarak dikkat çekmektedir. Bu bağlamda bakıldığında Almanya ve Lüksemburg KPÇ alanının öncüleri olarak değerlendirilebilir. Diğer yandan ülkelerin işbirliklerinde de Almanya - Lüksemburg 24 işbirliği yaparak bu değerlendirmeyi güçlendirmektedir.

Son olarak incelenen makaleler sonucunda KPÇ en az üç farklı şekilde kullanıldığı gözlenmektedir: (1) gerçek yaşam koşullarında (öğrenme, bilgi edinme ve karar alma gibi farklı odaklarla) bilişi incelemek için bir paradigma olarak, (2) genellikle bilgisayarda sunulan belli bir sınıf problemle uğraşırken sergilenen bir davranış tanımlayıcısı olarak ve (3) zekayla ilgili bir yetenek yapisı olarak.

$\mathrm{Bu}$ çalışmanın bir takım kısıtları da vardır. Bu çalışma konu ile ilgili genel yapıyı ortaya koymaktadır, ancak nitel yöntemler kullanılarak yapılacak çalışmalarda konu ile ilgili çalışan araştırmacıların çalışmaları derinlemesine incelenmelidir. Böylelikle konu ile ilgili değişkenler sistem yaklaşımı ile değerlendirilerek karmaşık problem çözmeyi etkileyen nedenler ve karmaşık problem çözmenin etkileri detaylı analiz edilebilir. Bunun yanında araştırmacılar farklı bilim alanlarında problem çözme araştırmalarını sistematik yazın tarama yöntemleri ile karşılaştırmalı olarak inceleyebilir. 


\section{KAYNAKÇA}

Aria M. \& Cuccurullo C. (2017). "Bibliometrix: An R-Tool for Comprehensive Science Mapping Analysis”. Journal of Informetrics 11/4 (2017) 959-975. doi:10.1016/j.joi.2017.08.007

Baggen Y., Mainert J., Lans T., Biemans H. J. A., Greiff S. \& Mulder M. (2015). "Linking Complex Problem Solving to Opportunity Identification Competence Within the Context of Entrepreneurship". International Journal of Lifelong Education 34/4 (2015) 412-429. doi:10.1080/02601370.2015.1060029

Beckmann J. F., Birney D. P. \& Goode N. (2017). "Beyond Psychometrics: The Difference Between Difficult Problem Solving and Complex Problem Solving”. Frontiers in Psychology 8 (2017) 17391751. doi:10.3389/fpsyg.2017.01739

Beckmann J. F. \& Guthke J. (1995). “Complex Problem Solving, Intelligence and Learning Ability”. Ed. P. A. Frensch \& J. Funke. Complex problem solving: the European perspective (1995) 177-200. New York.

Börner K., Chen C. \& Boyack K. W. (2005). "Visualizing Knowledge Domains”. Annual Review of Information Science and Technology 37/1 (2005) 179-255. doi: 10.1002/aris.1440370106

Caner T., Cohen S. K. \& Pil F. (2017). "Firm Heterogeneity in Complex Problem Solving: A KnowledgeBased Look at Invention”. Strategic Management Journal 38/9 (2017) 1791-1811. doi:10.1002/smj.2615

Care E., Scoular C. \& Griffin P. (2016). "Assessment of Collaborative Problem Solving in Education Environments”. Applied Measurement in Education 29/4 (2016) 250-264. doi:10.1080/ 08957347.2016.1209204

Cobo M. J., López-Herrera A. G. Herrera-Viedma E. \& Herrera F. (2011). "Science Mapping Software Tools: Review, Analysis and Cooperative Study Among Tools". Journal of the American Society for Information Science and Technology 62/7 (2011) 1382-1402. doi: 10.1002/asi.21525

Conley S. N., Foley R. W., Gorman M. E., Denham J. \& Coleman K. (2017). "Acquisition of T-shaped Expertise: An Exploratory Study”. Social Epistemology 31/2 (2017) 165-183. doi:10.1080/ 02691728.2016.1249435

Crane D. (1972). Invisible Colleges: Diffusion of Knowledge in Scientific Communities. Chicago 1972.

Danner D., Hagemann D., Schankin A., Hager M. \& Funke J. (2011). "Beyond IQ: A Latent State-Trait Analysis of General Intelligence, Dynamic Decision Making and Implicit Learning”. Intelligence 39/5 (2011) 323-334. doi:10.1016/J.INTELL.2011.06.004

de Bellis N. (2014). "History and Evolution of Biblio (metrics)". Ed. B. Cronin \& C. R. Sugimoto. Beyond Bibliometrics :Harnessing Multidimensional Indicators of Scholarly Impact (2014) 23-44.

Dörner D. \& Kreuzig H. W. (1983). "Problem Solving Ability and Intelligence”. Psychologische Rundschau 34/4 (1983) 185-192.

Dörner D. \& Güss C. D. (2013). "PSI: A Computational Architecture of Cognition, Motivation, and Emotion”. Review of General Psychology 17/3 (2013) 297-317. doi:10.1037/a0032947

Dörner D. \& Reither, F. (1978). "Über das Problemlösen in Sehr Komplexen Realitätsbereichen”. Zeitschrift Für Experimentelle Und Angewandte Psychologie: Organ Der Deutschen Gesellschaft Für Psychologie 4 (1978) 527-551.

Ederer P., Nedelkoska L., Patt A. \& Castellazzi S. (2015). “What Do Employers Pay For Employees' Complex Problem Solving Skills?”. International Journal of Lifelong Education 34/4 (2015) 430447. doi:10.1080/02601370.2015.1060026

Fischer A., Greiff S. \& Funke J. (2012). "The Process of Solving Complex Problems”. The Journal of Problem Solving 4/1 (2012) 19-42. doi:10.7771/1932-6246.1118

Fischer A., Greiff S., Wüstenberg S., Fleischer J., Buchwald F. \& Funke J. (2015). “Assessing Analytic and Interactive Aspects of Problem Solving Competency”. Learning and Individual Differences 39 (2015) 172-179. doi:10.1016/J.LINDIF.2015.02.008

Fischer A., Holt D. V. \& Funke J. (2015). "Promoting the Growing Field of Dynamic Decision Making”. Journal of Dynamic Decision Making 1/1 (2015) 1-3. doi:10.11588/jddm.2015.1.23807

Frischkorn G. T., Greiff S. \& Wüstenberg S. (2014). "The Development of Complex Problem Solving in Adolescence: A Latent Growth Curve Analysis”. Journal of Educational Psychology 106/4 (2014) 1007-1020. doi:10.1037/a0037114 
Funke J. (1991). "Solving Complex Problems: Exploration and Control of Complex Systems”. Ed. R. J. Sternberg \& P. A. Frensch. Complex Problem Solving: Principles and Mechanisms, (1991) 185-222. New York.

Funke J. (2001). “Dynamic Systems As Tools For Analysing Human Judgement”. Thinking and Reasoning 7/1 (2001) 69-89. doi:10.1080/13546780042000046

Funke J. (2010). “Complex Problem Solving: A Case for Complex Cognition?”. Cognitive Processing 11/2 (2010) 133-142. doi:10.1007/s10339-009-0345-0

Greiff S., Fischer A., Wüstenberg S., Sonnleitner P., Brunner M. \& Martin R. (2013). “A MultitraitMultimethod Study of Assessment Instruments for Complex Problem Solving”. Intelligence 41/5 (2013) 579-596. doi:10.1016/J.INTELL.2013.07.012

Greiff S., Holt D. V. \& Funke J. (2013). "Perspectives on Problem Solving in Educational Assessment: Analytical, Interactive and Collaborative Problem Solving”. The Journal of Problem Solving 5/2 (2013) 71-91. doi:10.7771/1932-6246.1153

Greiff S., Stadler M., Sonnleitner P., Wolff C. \& Martin R. (2015). "Sometimes Less is More: Comparing the Validity of Complex Problem Solving Measures”. Intelligence 50 (2015) 100-113. doi:10.1016/J.INTELL.2015.02.007

Greiff S., Wüstenberg S., Csapó B., Demetriou A., Hautamäki J., Graesser A. C. \& Martin R. (2014). "Domain-General Problem Solving Skills and Education in the 21st Century". Educational Research Review 13 (2014) 74-83. doi:10.1016/j.edurev.2014.10.002

Güss C. D., Tuason M. T. \& Gerhard C. (2009). “Cross-National Comparisons of Complex ProblemSolving Strategies in Two Microworlds”. Cognitive Science 34/3 (2009) 489-520. doi:10.1111/j.15516709.2009.01087.x

Güss C. D. (2011). “Fire and Ice: Testing a Model on Culture and Complex Problem Solving”. Journal of Cross-Cultural Psychology $42 / 7$ (2011) 1279-1298. doi:10.1177/0022022110383320

Hagemann N. \& Kirschke S. (2017). "Key Issues of Interdisciplinary NEXUS Governance Analyses: Lessons Learned from Research on Integrated Water Resources Management”. Resources 6/1 (2017) 9-16. doi:10.3390/resources6010009

Hagemann V. \& Kluge A. (2017). "Complex Problem Solving in Teams: The Impact of Collective Orientation on Team Process Demands”. Frontiers in Psychology 8 (2017) 1730-1748. doi:10.3389/ fpsyg.2017.01730

Huber O. (1994). “Decision Behavior in a Multistage Investment Task”. Acta Psychologica 85/2 (1994) 139-154. doi:10.1016/0001-6918(94)90029-9

Kirschke S., Newig J., Völker J. \& Borchardt D. (2017). "Does Problem Complexity Matter for Environmental Policy Delivery? How Public Authorities Address Problems of Water Governance”. Journal of Environmental Management 196 (2017) 1-7. doi:10.1016/J.JENVMAN.2017.02.068

Kröner S., Plass J. L. \& Leutner D. (2005). “Intelligence Assessment with Computer Simulations”. Intelligence 33/4 (2005) 347-368. doi:10.1016/J.INTELL.2005.03.002

Marshall S. P. (2009). "Re-Imagining Specialized STEM Academies: Igniting And Nurturing Decidedly Different Minds, by Design”. Roeper Review 32/1 (2009) 48-60. doi:10.1080/02783190903386884

Merton R. K. (1957). "Priorities in Scientific Discovery: A Chapter in the Sociology of Science". American Sociological Review 6 (1957) 635-659. doi:10.2307/2089193

Nair K. U. \& Ramnarayan S. (2000). "Individual Differences in Need for Cognition and Complex Problem Solving”. Journal of Research in Personality 34/3 (2000) 305-328. doi:10.1006/JRPE.1999.2274

“PISA 2015”. (2019, April 15) Kaynak: http://www.oecd.org/pisa/pisa-2015-results-in-focus.pdf

Schoppek W. \& Fischer A. (2017). “Common Process Demands of Two Complex Dynamic Control Tasks: Transfer is Mediated by Comprehensive Strategies”. Frontiers in Psychology (2017) 8 21452157. doi:10.3389/fpsyg.2017.02145

Schult J., Stadler M., Becker N., Greiff S. \& Sparfeldt J. R. (2017). "Home Alone: Complex Problem Solving Performance Benefits from Individual Online Assessment”. Computers in Human Behavior 68 (2017) 513-519. doi:10.1016/J.CHB.2016.11.054 
Schweizer F., Wüstenberg S. \& Greiff S. (2013). "Validity of the MicroDYN Approach: Complex Problem Solving Predicts School Grades Beyond Working Memory Capacity”. Learning and Individual Differences 24 (2013) 42-52. doi:10.1016/J.LINDIF.2012.12.011

Sinnott J., Tobin E., Chrzanowska E. \& Hilton S. (2017). "The Relationship between Attachment Style and Postformal Thought”. Journal of Adult Development 24/4 (2017) 239-251. doi:10.1007/s10804-0179262-0

Sonnleitner P., Brunner M., Keller U. \& Martin R. (2014). "Differential Relations between Facets of Complex Problem Solving and Students' Immigration Background". Journal of Educational Psychology 106/3 (2014) 681-695. doi:10.1037/a0035506

Steiner G. \& Posch A. (2006). "Higher Education for Sustainability by means of Transdisciplinary Case Studies: An Innovative Approach for Solving Complex, Real-World Problems”. Journal of Cleaner Production 14/9-11 (2006) 877-890. doi: 10.1016/J.JCLEPRO.2005.11.054

“The Future of Jobs Report 2018 Insight Report Centre for the New Economy and Society”. (2019, April 15). Kaynak: http://www3.weforum.org/docs/WEF_Future_of_Jobs_2018.pdf

Weigelt C. \& Sarkar M. (2012). "Performance Implications of Outsourcing for Technological Innovations: Managing the Efficiency and Adaptability Trade-Off”. Strategic Management Journal 33/2 (2012) 189216. doi:10.1002/smj.951

Wenke D., Frensch P. A. \& Funke J. (2005). “Complex Problem Solving and Intelligence: Empirical Relation and Causal Direction”. Ed. R. J. Sternberg \& J. E. Pretz. Cognition and Intelligence: Identifying the Mechanisms of the Mind (2005) 160-187. New York.

Wüstenberg S., Stadler M., Hautamäki J. \& Greiff S. (2014). "The Role of Strategy Knowledge for the Application of Strategies in Complex Problem Solving Tasks”. Technology, Knowledge and Learning 19/1-2 (2014) 127-146. doi:10.1007/s10758-014-9222-8 